\title{
El Rococó Germánico y la vida de San Agustín en la pintura cusqueña: lo profano como alegoría cristiana*
}

Ricardo Estabridis

\section{Introducción}

La representación del santo africano Agustín de Hipona, ya sea en forma individual o integrando diversos momentos de su vida, ha sido fuente de inspiración de muchos artistas a lo largo de los siglos desde la quinta centuria de nuestra era, como aquel fresco representado en su estudio en el Palacio Lateranense de Roma. ${ }^{\prime}$ El arte europeo a través de los diferentes estilos ha dejado importantes muestras en las expresiones pictóricas y escultóricas. Una serie única de la vida de Agustín en presentaciones por separado se aprecia en los relieves en mármol del Maestri Campionesi (1362) en la Basílica de S. Pietro en Ciel d'Oro en Pavía, y en pintura renacentista en la serie al fresco que realizó Benozzo Gozzoli en la iglesia agustina en San Giminiano en la Toscana. Con respecto al siglo XVIII hay que mencionar a Matthäus Günther, uno de los fresquistas más prolíficos de Baviera, con la serie que decora la colegiata de Indersdorf, entre otras. ${ }^{2}$

A esa rica iconografia agustiniana, Hispanoamérica cristianizada hizo significativos aportes, en especial los pintores cusqueños en el virreinato peruano quienes nos dejaron, aparte de las representaciones individuales, setenta y cinco lienzos en dos series del siglo XVIII, una conservada en los claustros del convento de San Agustín de Lima y la otra en el convento de La Merced del Cusco, en las que jugaron un papel no menos importante que las pinturas y esculturas ya citadas, los grabados flamencos y germánicos.

El presente estudio no va dirigido a la serie pintada por Basilio Pacheco para los agustinos de Lima ${ }^{3}$, tema que hemos trabajado después de la última restauración de las obras y cuyo resultado se encuentra en prensa, sino a la serie de la vida de San Agustín que conservan los mercedarios en el claustro de su convento en el Cusco, la que sí es inédita. Mientras que la serie ubicada en Lima está relacionada con los grabados flamencos del siglo XVII, la segunda tiene como fuente de inspiración referencial a los grabadores de Augsburgo del siglo XVIII.

El convento de San Agustín del Cusco, según el cronista Calancha, se fundó el 11 de junio de 1559. ${ }^{4}$ Después de él, el documento más importante es la crónica anónima ${ }^{5}$ que nos habla de la destrucción del convento en el devastador terremoto de $1650 \mathrm{y}$ del encargo de la serie de la vida del santo para el convento limeño en 1745. Algunos estudiosos plantearon

Artículo basado en la ponencia presentada en el IV Congreso Internacional del Barroco Iberoamericano realizado en Ouropreto, Brasil en junio del 2006.

1 ITURBE, Antonio: "Iconografia de San Agustín. Atributos y temas o títulos iconográficos...En Iconografia Agustiniana (Roma 22-24 de noviembre de 2000). Actas del XVI Congreso Internacional de Historia de la Orden de San Agustín. Roma, edición preparada por Rafael Lazcano, 2001, p.20.

2 REISINGER, Ferdinand: "Das Leben des H1. Augustinus en 17 Cupfern (Die Serie del Klauber-Stiche von 1758)". En: Augustinus - der Prediger. IN UNUM CONGREGATI, 37. JAHRGANG 1990, HEFT 3/4-90, p, 35.

3 ANÓNIMO: Anales del Cuzco 1600-1750. Lima, 1901, p.104. También ver: MESA, José de; GISBERT, Teresa: Historia de la Pintura Cuzqueña. Lima, Fundación Augusto N. Wiese, 1982, T.I,, p.201. COURCELLE, Jean y Pierre: Iconographie de Saint Augustin. Les cycles du XVIII siecle allemand, París 1980.

4 CALANCHA, Fray Antonio de la: Crónica Moralizada.... Barcelona, 1639, T. I. Lima, 1653, T.II, p. 499.

5 ANÓNIMO: Ob. Cit. 1901, p.346. 
en décadas pasadas que estos lienzos ya existían antes del terremoto de 1650 y que después de este suceso fueron trasladados al convento de la Merced del Cusco, confundiendo con ello las dos series en época y ubicación. ${ }^{6}$

José María Blanco en 1834, en un diario de viaje del presidente Orbegoso, nos alcanza información en torno al convento de San Agustín del Cusco. Menciona que el convento se abandonó en la época del ex general Gamarra y sirvió de cuartel desde 1827. Al referirse al convento de La Merced nos dice:

En los claustros del segundo patio están colocados los cuadros de la vida de San Agustín, que son mejores que los de la vida de San Pedro Nolasco, y fueron comprados al Estado el año de 1831 por el padre Comendador Nieto.

Todo parece indicar que recién se trasladaron al convento mercedario los lienzos de la serie que nos ocupa en el siglo XIX. Ello ayuda igualmente a reforzar que las pinturas no se realizaron en el siglo XVII como algunos afirman, sino en la segunda mitad del siglo XVIII, en fecha posterior a los que hizo Pacheco para Lima, como los caracteres estilísticos lo ponen de manifiesto. La desaparición del archivo conventual del Cusco y la ausencia de firmas la mantienen en el anonimato. ${ }^{8}$

Si la serie de pinturas de Basilio Pacheco realizada en la primera mitad del siglo XVIII, aparte de tener como fuente los grabados del flamenco Schelte Adams Bolswert, incluyó siete temas novedosos como aportes iconográficos significativos a los ya doscientos veintiséis temas documentados en el mundo de la vida de San Agustín, ${ }^{9}$ la serie del pintor anónimo que nos ocupa en este estudio, en el desarrollo de sus treinta y siete lienzos, aparte de su inspiración parcial en algunos grabados alemanes, también hará importantes aportes a la iconografia del santo africano, como por ejemplo aquel tema inédito de su entrada triunfal a Hipona como Obispo.

\section{Los Klauber como difusores del pensamiento agustino a través del grabado rococó}

Uno de los centros europeos más importantes del grabado en cobre en el siglo XVIII fue la escuela de Augsburgo y en ella hubo una familia de grabadores con el apellido Klauber, que aparte de sus dotes artísticas desarrollaron y difundieron una convicción católica bien marcada a través de una gran producción de estampas; por ello, no es extraño encontrar en los grabados después de sus firmas el abreviado "cath", católico. Su repertorio temático en la segunda mitad del siglo es rico y variado, con grandes ciclos bíblicos del Antiguo y Nuevo Testamento, del santoral católico, sobre los sacramentos, sobre las verdades de la fe, sobre las obras de la misericordia, entre muchos otros. Todas estas estampas llegaron a Hispanoamérica, pero sin duda las que más se difundieron fueron las de temas marianos, ciclos sobre la vida de la Virgen y en especial las alegóricas sobre las letanías lauretanas. ${ }^{10}$

Los ciclos de la vida de Agustín desarrollados en los lienzos cusqueños, a diferencia de las pinturas europeas, incluyen su vida pagana, desde su árbol genealógico, su nacimiento en Tagaste, su formación en Madaura, en Cartago y su gran progreso intelectual que lo lleva a Roma y Milán, en el marco de un pensamiento maniqueo. La intencionalidad indudablemente fue condicionada por la evangelización, como modelo a seguir; por ello, tampoco dejan de lado su conversión y su crecimiento en dignidades en el seno de la iglesia católica, hasta convertirse en uno de sus cimientos más sólidos en cuanto a la cercanía a Dios en su esencia, así como en la defensa de los dogmas y verdades de la fe contra los heresiarcas.

6 CORNEJO BOURONCLE, Antonio: Derroteros del Arte Cuzqueño. Cuzco. 1960, p.3.

7 BLANCO, José María: Diario de viaje del Presidente Orbegoso al sur del Perú. Lima, Instituto Riva Agüero, 1974. p.232.

8 VILLAREjO, Avencio: Los Agustinos en el Perú (1548 - 1965). Lima, Edit. Ausonia, 1965, p.89.

9 ITURBE: Ob. Cit., 2001, p.24.

10 DORNN, Francisco Xavier: Letaniae Laurentanae, Viena, 1758. 
Las limitaciones de espacio hacen que nos centremos en la muestra específica seleccionada para esta edición, es decir los trece lienzos de la serie de la vida de San Agustín conservados en el convento de La Merced del Cusco, que tomaron como fuente de inspiración parte de la serie de grabados sobre el tema, desarrollados en la escuela de Augsburgo por los hermanos Josef Sebastián Klauber (1700-1768) y Johann Bapist Klauber (1712-1787) y la importancia que ellos tuvieron, no sólo en el aspecto formal, como ejemplo de la introducción del gusto rococó en parte de la escuela cusqueña, sino como paradigmas de la aplicación en el arte del pensamiento agustino, donde las fuentes iconográficas paganas son reinterpretadas en el mundo cristiano.

San Agustín era un retórico, pero al igual un hombre muy contemplativo que pensaba mucho sobre la importancia del lenguaje plástico y el papel de la imagen en su función como símbolo o alegoría. Al igual que él otros estudiosos de la época, c.400, como Aurelio Prudencio Clemente, de origen hispano escribe: La Psicomachia en la que en forma alegórica habla de la lucha entre las virtudes y los vicios; asimismo, Martianus Capella, gramático norteafricano del siglo V, escribe el tratado alegórico: De nuptis Philologiae et Mercurio, donde describe a las siete artes liberales. Son algunas de las fuentes literarias inspiradoras tempranas, del arte cristiano alegórico y emblemático. ${ }^{11}$

Los grabadores Klauber ejecutaron las imágenes que corresponden a escenas de la vida de San Agustín, acompañadas por frases sugeridas por las autoridades religiosas e inventadas por Johann Anwander, ${ }^{12}$ y con ello lograron, hace ya doscientos cincuenta años atrás, en 1758, trasformar el lenguaje rico y abundante de Agustín en la forma compleja del rococó germánico, a través de imágenes-discursos, como emblemas moralizantes, en diecisiete grabados en cobre donde veremos transformados en alegorías cristianas a la diosa Minerva, al dios Pan y a Eros, entre otros seres del Panteón clásico. Las letras P.T.Z.A. en el grabado de la estampa que inicia la serie, donde Agustín es representado como Padre de la Iglesia Católica, como "Lux Doctorum" y "Fulmen Haereticorum", corresponden al editor Peter Trayn Zullende de Augsburgo.

De los temas de los dieciséis grabados que siguen a la mencionada estampa inicial, serán trece los tomados como modelos en Cusco, con excepción de los pasajes referentes a la muerte de su madre, la ordenación de Agustín como presbítero, así como las escenas donde Agustín entrega la regla de su Orden y el momento en que es consagrado obispo.

\section{La pintura cusqueña en el siglo XVIII y la influencia del rococó}

La pintura cusqueña en el siglo XVIII, después de las marcadas influencias de los estilos europeos tanto de origen flamenco como español, derivará hacia estereotipos en las figuras de belleza esquemática, de vestiduras en colores luminosos y formas que han dejado atrás el modelado de marcado carácter claroscurista, así como el respeto a lo académico en la construcción del espacio y la perspectiva. Desde fechas tempranas predomina en el mercado el encargo a los pintores indios que han ganado posición desde finales del siglo anterior con respecto a los pintores españoles. Tal como sucede en la capital con pintores limeños como Cristóbal Lozano ${ }^{13}$, los pintores cusqueños en un sentido de afirmación, son llamados como peritos tasadores para hacer la valorización de las obras de arte de distinguidas personalidades, eclesiásticas y civiles. Asimismo sus obras son requeridas cada vez más en otras latitudes.

Las tradiciones del siglo anterior se mantienen en el Cusco en algunos pintores como Basilio Pacheco, en la ejecución de series de pinturas inspiradas en paisajes relacionados con las estampas de origen flamenco, sin ser fiel a ellas, tal como en las pinturas de la vida

11 ESTEBAN LORENTE, Juan Francisco: Estudios de Iconologia. Madrid. Edit. Istmo, 1998, pp. 383 y ss.

12 REISINGER: Ob. Cit. 1990, p.35. También ver CORCELLE: Ob. Cit. 1980, p.37.

13 ESTABRIDIS CÁRDENAS, Ricardo: "Cristóbal Lozano, paradigma de la pintura limeña del siglo XVIII". En: Actas del III Congreso Internacional del Barroco Iberoamericano. Sevilla, Edit. Giralda , 2001, T. I., p. 345. 
de San Agustín para su convento limeño. Sin embargo, en él, al paisaje idílico le gana en espacio el marco arquitectónico, donde se desarrollan las escenas en modelado correcto y rico colorido.

El pintor Marcos Zapata es quien marca la pauta diferencial con respecto a Pacheco y otros contemporáneos, no sólo en la falta de los brocateados característicos del siglo XVIII en esta escuela, sino que además nos sirve de paradigma en el uso de los grabados de la escuela de Augsburgo al realizar en 1755 cincuenta lienzos sobre las letanías lauretanas para la catedral del Cusco, inspirados en la serie en cobre: "Elogia Mariana", "Inventa et delineata" por C.B. Scheffler e impresa por Martino Engelbrecht, en 1732. Se hace evidente en las pinturas y en sus fuentes la tendencia de la escuela germana a utilizar temas paganos clásicos en su defensa de la fe; es una clara muestra el tema "Speculum Justitiae" que opone al símbolo pagano de la exaltación del ego en la figura de Narciso mirándose en las aguas, en contraste con el ejemplo cristiano de María que se mira en el espejo de la entrega a la suprema justicia, con plena renuncia del yo. No faltan en ellos los letreros latinos que marcan la pauta para la compleja lectura alegórica. ${ }^{14}$

Uno de los pintores cusqueños del siglo XVIII que más claramente muestra su gusto por la ornamentación rococó, es Antonio Vilca. Se conserva de él en la iglesia de Pujiura un ciclo de pinturas sobre las Letanías de la Virgen, inspirados en una serie grabada por los hermanos Klauber denominada: "Letaniae Laurentanae", publicada por Francisco Xavier Dornn. ${ }^{15}$ Se documentan varias ediciones de este libro, entre ellas María José del Castillo y Utrilla cita una edición de 1750 donde exalta los grabados de los Klauber como una de las muestras más ricas de la iconografía mariana del siglo XVIII. ${ }^{16}$

Las pinturas de la vida de San Agustín del convento de La Merced del Cusco fueron realizadas en este contexto del siglo XVIII cusqueño por un pintor aún no identificado, pero que consideramos se encuentra próximo a las características formales de Antonio Vilca y su círculo.

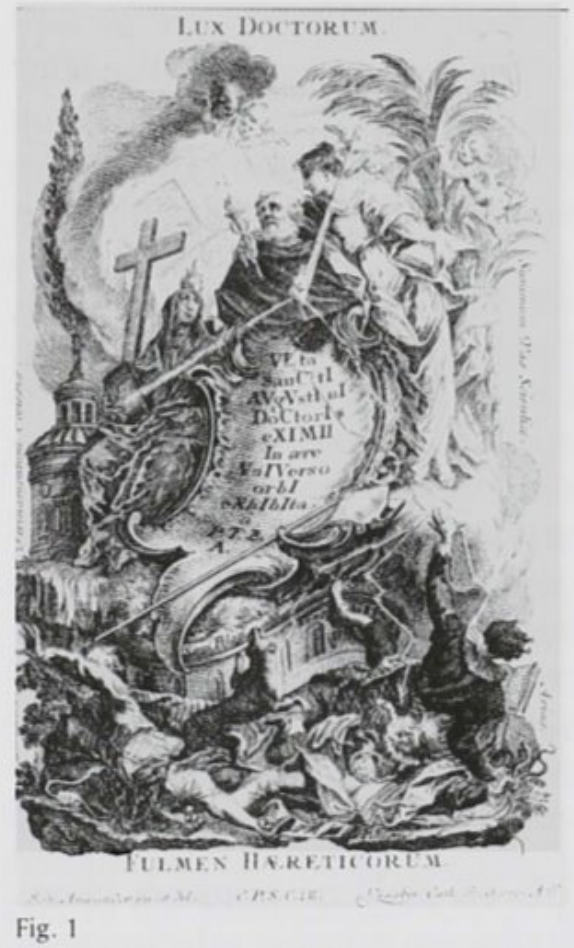

\section{Análisis iconográfico de las pinturas de la vida de San Agustín en sus fuentes germanas 1. San Agustín luz de los doctores. Fin de los Herejes} Iniciamos nuestro análisis con el lienzo que desarrolla un tema de carácter alegórico y sirve como presentación del significado e importancia que tiene el Santo de Hipona para la iglesia católica, inspirado en la primera estampa de la serie de los Klauber. El pintor anónimo cusqueño desarrolla aquí y en todas las otras pinturas una composición en formato apaisado, a diferencia de las estampas que presentan una configuración en vertical y no copia las leyendas en latín, sólo considera una síntesis de ellas en algunas cartelas escritas en castellano.

En este primer grabado (Fig.1) el título superior lo destaca como la luz de todos los doctores de la Iglesia y el inferior como exterminador de herejes; para ello, en esta imágen-discurso aparece una gran cartela central

14 MESA,GISBERT: Ob. Cit. 1982, T.I., p.210.

15 Ibídem, p.219.

16 CASTILLO Y UTRILLA, María José del: "Iconografía de la Letanía Lauretana según Dornn". En Cuadernos de Arte e Iconografia. Madrid, T.II-3, 1989. También ver: SEBASTIAN, Santiago: "La imprenta en Valencia como difusor del espíritu Rococó". En: Revista Cimal. Num. 2, Valencia, 1979, pp. 34-36. y del mismo autor: "La influencia germánica de los Klauber en Hispanoamérica". En: Boletin del Centro de Investigaciones Históricas y Estéticas. $\mathrm{N}^{\circ} 14$, Caracas, Universidad Central de Venezuela, 1972, p. 61 y ss. 
de marco en rocalla cuya traducción del latín es: "La vida de San Agustín, doctor notable, estimula al universo y es un ejemplo universal. P.T.Z.A".

Las iniciales finales, como ya hemos anotado corresponden al editor Peter Trayn Zullende de Augsburgo. Alrededor de ella las figuras de Agustín, con las alegorías de la Sabiduría y de la Iglesia en un plano celeste, separadas por un muro de los herejes Donato, Pelagio y Arrio que aparecen fulminados por rayos en la zona inferior. Dos leyendas, una al lado de la Sabiduría: "El conocimiento nos lleva a la cima" y otra al lado de la Iglesia: "El auxilio de la Iglesia”, son escuetas pero elocuentes.

En la pintura (Fig.2) se ha cambiado el texto en latín de la cartela por uno en castellano que dice:

\begin{abstract}
El gran padre agustino inspirado de Minerva diosa de la sabiduría, juntamente con la iglesia católica triunfa de los enemigos de ella, aterrándolos con sus escritos y libros; dejando a la fe y religión tranquila y pacífica: como lo hace su religión sagrada e hijos de ella.
\end{abstract}

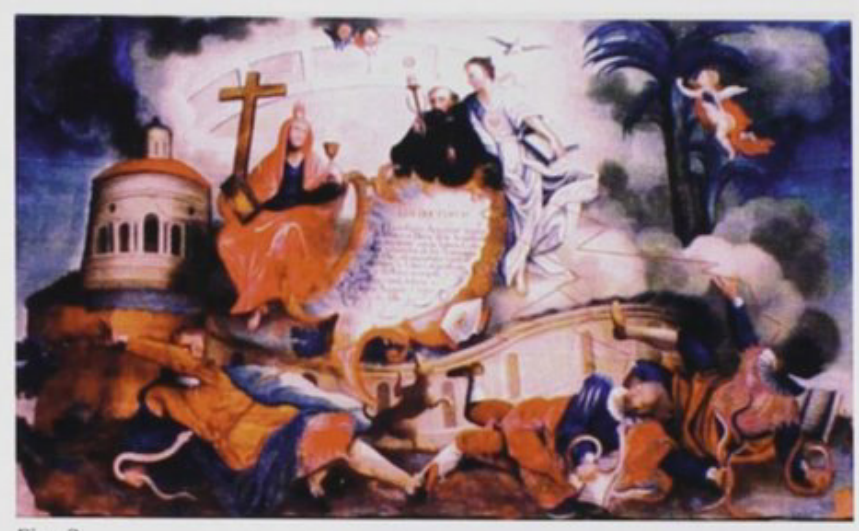

Fig. 2

Aquí se reinterpreta en código cristiano a la diosa pagana Minerva como alegoría de la Sabiduría, con un libro abierto en la mano izquierda y una antorcha con dos sierpes entrelazadas, sobre la que está el sol. Este atributo no común en las manos de la diosa, nos permite interrelacionar el símbolo de Mercurio con el de Minerva, andrógino llamado en el siglo XVI Hermathena, que fue representado en el Palacio Farnesio en Caprarola en la figura de los dos dioses (Fig.3), donde la lectura nos lleva a interpretarlo como: la rapidez de la elocuencia de Mercurio y la inmutabilidad de la sabiduría de Minerva, como símbolos propios del doctor de Hipona. ${ }^{17}$ Sobre el hombro de la Sabiduría se pintó el Espíritu Santo que ilumina el corazón ardiente de Agustín y una gran palmera, símbolo de su triunfo. Al otro costado del santo africano la alegoría de la Iglesia, con un libro, una cruz y una lengua de fuego en la cabeza, al lado de un edificio circular y un ciprés, relacionado con

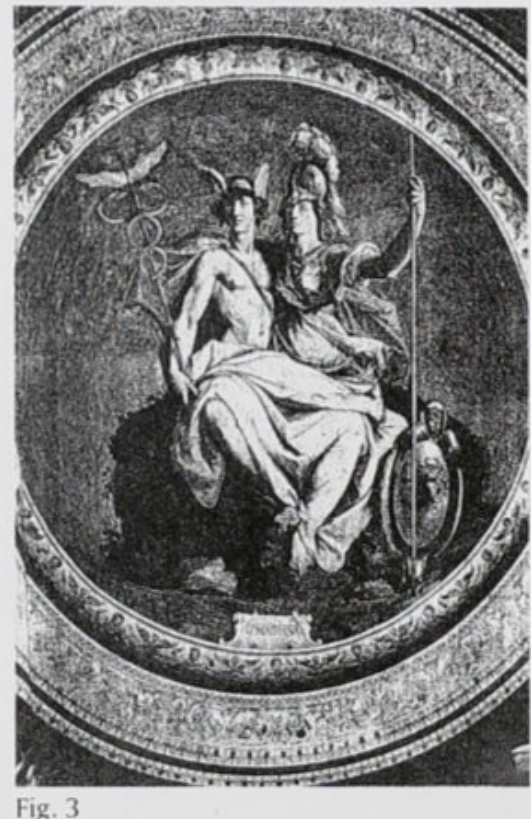
la muerte y en este caso reinterpretado como la elevación e inmortalidad dada por la fe en la Iglesia. Los enemigos caídos en el plano terrestre representan a las cabezas de las tres principales doctrinas contra los que luchó Agustín, la de los maniqueos, que atacan la potencia de Dios, el donatismo que destruye la autoridad y unidad de la Iglesia, y los pelagianos que niegan la necesidad de la gracia y consecuentemente la redención. ${ }^{18}$

\title{
2. Muerte de Patricio. Educación de Agustín por Mónica
}

Después del tema iconográfico de la presentación del Padre de la Iglesia se omite en los grabados otros temas desarrollados en la pintura cusqueña, como el árbol genealógico, su nacimiento y la educación en la escuela de Madaura, hasta este lienzo donde se representan dos escenas separadas por marcos de rocalla, en una la muerte de su padre y en la otra

17 ESTEBAN LORENTE: Ob. Cit. 1998, p.462.

18 CAVAZZANA, Juan E.: "San Agustín, la vida, la obra y su influencia". En: Revista de la Universidad Católica del Perú. Tomo III. N¹3. Año IV, Lima, 1935, p.159. 
la educación de Agustín por su madre católica. El pintor cusqueño para este lienzo sólo ha tomado como fuente de inspiración, para el tema de la educación, el grabado segundo de los Klauber. La leyenda del lienzo es ilegible por ello para su lectura nos basaremos exclusivamente en el grabado. En la parte superior el título principal del grabado da cuenta en latín que: "Agustín Aurelio nació en Tagaste, Numidia el 13 de noviembre en el año del señor 354. Mónica su madre mantenía en alto el nombre de Jesús". ${ }^{19}$

Este escrito es complementado con la leyenda inferior que en líneas generales alude a un texto tomado de Las Confesiones (Lib. III, cap. IV), cuando Agustín después de su conversión le da el lugar que le corresponde a su madre, ya que a Cristo lo bebió desde niño de la leche materna.

En el lienzo y estampa la escena se desarrolla en una habitación de planta mixtilínea, enmarcada en compleja rocalla. En ella Mónica con la mano derecha señala el monograma de Cristo en el pecho del niño Agustín y con la izquierda hacia el cielo donde entre nubes recostada aparece una figura alegórica de la Iglesia Católica con cetro, coronada con el triangulo de la Trinidad de cuyos labios se desprende: "Ese es mi elegido para Ilevar mi nom-

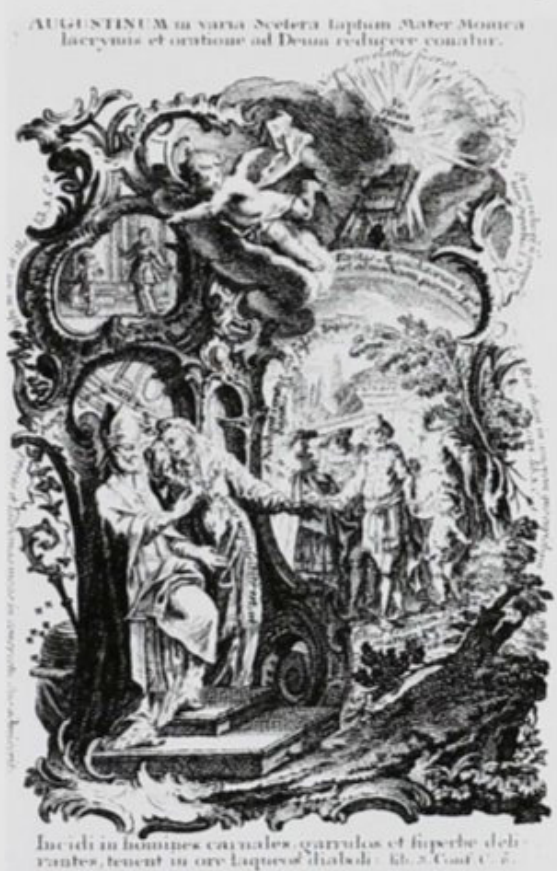
Fig. 4

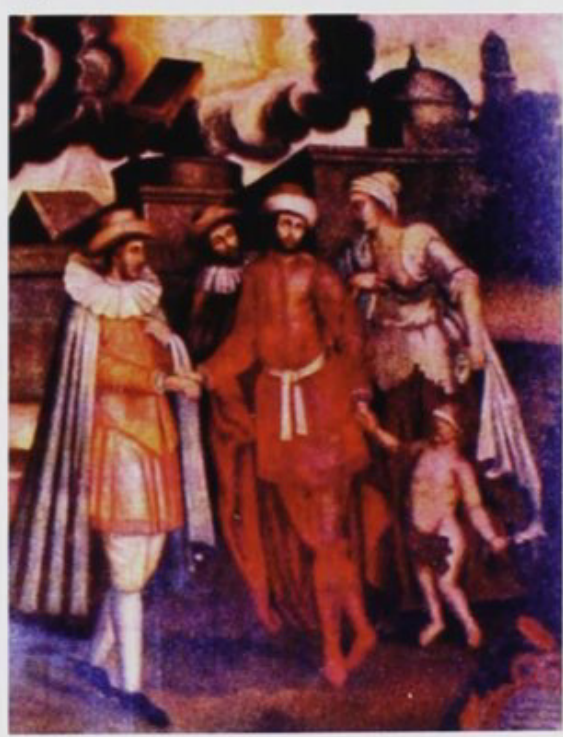

Fig. 5 bre". Cerca de ella un par de angelitos meten el corazón en llamas de Agustín en un ánfora.

Próxima a Agustín una pila bautismal con la leyenda tomada de Las Confesiones (Lib. I, cap. XIII): “Se postergó mi purificación". Otras pequeñas leyendas refuerzan la formación y la importancia que tendrán sus futuros escritos contra los herejes que aparecen en una pequeña escena a la espalda de su madre, donde se afirma que quienes no estén con ellos no estarán en la Iglesia.

\section{Lágrimas de Mónica ante San Ambrosio. Agustín de la mano del amor profano}

La cartela determina el título del lienzo ya que en ella se lee:

San Ambrosio consuela a Mónica y predice la conversión de su hijo agustino. Mónica en presencia del santo llora y derrama lágrimas deseando la conversión de agustino. Agustino...... no se determina convertirse. Amigos de Agustino que le persuaden la religión cristiana. Ama de leche de Agustino que le impide su conversión. Cupido, amor profano que lo detiene para que no se convierta.

Las dos escenas que integran la composición se desarrollan en el marco de un paisaje (Fig.4). A la izquierda en arquitectura escenográfica rococó, Mónica llora ante el obispo, mientras que hacia la derecha aparece Agustín de la mano del Amor Profano en la figura de cupido con los ojos vendados, acompañado de dos amigos y seguido por una mujer que le muestra un pecho. El tema de cupido con los ojos vendados como símbolo del amor profano o terrenal se define prácticamente en el Renacimiento donde su significado específico de una forma de amor sensual, se contrastaba deliberadamente con otro de amor más alto, espiritual, platónico, sagra-

19 Numidia es hoy Souk-Ahras, Argelia. 
do. Ello es producto de todo un proceso evolutivo que se origina en la antiguiedad clásica donde no se da en el arte el cupido ciego, hasta la edad media que con carácter moralista cristiano se le relaciona con la noche, la muerte, la fortuna y la infidelidad, personificaciones ciegas. ${ }^{20}$

Las leyendas en latín que aparecen en el grabado y no en el lienzo, nos ayudan en la lectura de la creación (Fig.5). La leyenda superior nos habla sobre el sufrimiento de Mónica por su hijo maniqueo y la inferior, tomada de Las Confesiones, (Lib.3, cap. VI) habla de su arrepentimiento. Es la época en que Agustín pertenecía a la secta de los maniqueos ${ }^{21}$ y se había precipitado en el amor terreno. En esta etapa de su vida al leer el Hortensio de Cicerón se revela ante él el ideal griego de la Sophia, del conocimiento desinteresado de la belleza platónica del intelecto y que por esa vía el hombre sapiente se convierte casi en un Dios. ${ }^{22}$

\section{Conversión de Agustín}

Esta escena de las dos series tanto en cobre como en lienzo, representa el momento decisivo de su vida, destacada porque Agustín vence toda duda y deja el maniqueísmo de lado. No olvidemos que previo a ello había leído a Plotino quien señala la presencia del bien como fuente y principio de toda belleza y posteriormente a Platón, a quien recién lee a sus treinta y dos años y resulta para él toda una revelación e influencia, por ello lo cita con frecuencia pero conciliándolo con Dios. El supo adaptar como nadie las aportaciones de los griegos a las necesidades de la dogmática de los cristianos. Se considera por ello al cristianismo como un platonismo coronado por la gracia. ${ }^{23}$ Ello y la lectura de las epístolas de San Pablo a los romanos culminan su plena conversión (Rom. XIII-14). En la leyenda superior de la estampa remarcan que fue el 28 de mayo del 386.

El tema dio lugar a que de acuerdo al lenguaje del gusto de la época, la imagen alegórica enriqueciera el momento en la creación grabada por los Klauber (Fig.6) y se desarrollara ampliamente en la pintura que lo tomó como fuente (Fig.7). La escena tiene por marco el jardín de la casa de su amigo Alipio, en Milán, donde Agustín vence su culpa con los auxilios de la Gracia, representada por la alegoría de la Castidad $^{24}$ quien le dice: "Tolle lege, tolle lege", Toma y lee, toma y lee, refiriéndose a la epístola de San Pablo, rodeada de una corte de vírgenes con ramas de laurel y palmas. A su lado su amigo Alipio quien también se convierte.

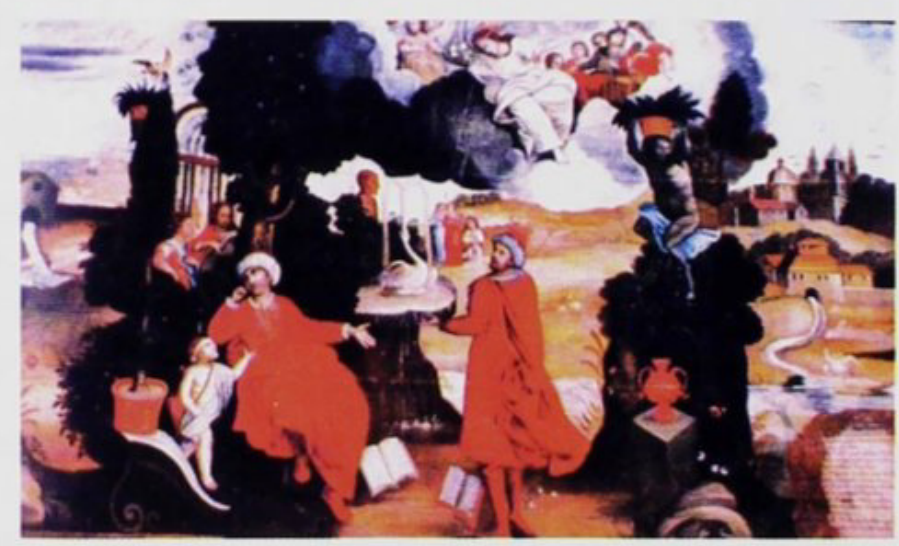

Fig. 7

20 PANOFSKY, Erwin: Estudios sobre Iconología. Madrid, Edit. Alianza Universidad, 1980, p.139.

21 Secta religiosa fundada por el persa Manes en el siglo III, que sostenía la dualidad del hombre entre el bien y el mal, creyendo que el espíritu del hombre es de Dios, pero el cuerpo del hombre es del demonio.

22 ESCLASANS, Agustin: San Agustin. Barcelona, Edit. Seix Barral, 1947, p. 34.

23 CAVAZZANA, J.: Ob. Cit. 1935, T. III, №13, Año IV, p. 158 y ss. Ver también JOLIVET, Rgis: San Agustín y el neoplatonismo cristiano. La Plata, 1941, p. 101

24 RIPA, Cesare: Iconologia. Madrid, edit Akal, 1987, T.I, p. 181. A la Castidad la describe vestida de blanco con una rama de cinamomo. Este árbol tiene una resina aromática que según algunos se cree que es la mirra y de cuyas semillas se hacen cuentas del rosario. 
Las tentaciones no faltan en las figuras de las mujeres detrás del árbol que cobija a Agustín quienes le dicen, según la leyenda en latín: ¿nos abandonas? Mientras que el amor profano va a su lado, y cerca de él una leyenda que pregunta: ¿imaginas que vas a poder vivir sin estas cosas? Refuerzan el mensaje un macetero con un ciprés donde se posa un cuervo; ese árbol, en lo pagano era símbolo de Plutón y por ello se le relaciona con lo fúnebre ${ }^{25}$, y el cuervo en el mundo cristiano se le consideró como símbolo de la soledad, por ser un ave solitaria. ${ }^{26}$

Hacia la derecha de la composición, detrás de Alipio destaca un arbusto sobre el cual un ser mitológico con macetero en la cabeza, que hemos identificado como el dios Pan, ya que tiene pies caprinos, dos cuernos y lleva como atributo colgada de un cinto terciado una flauta o siringa, nombre de la ninfa, compañera de Diana, de quien se enamoró y que para salvarla de él la convirtieron en caña. Al soplar una de estas cañas nació el sonido de la flauta de Pan. Personaje amante de la danza que retoza en los prados persiguiendo a las ninfas, pero a su vez es el guardián y protector de los rebaños. La relación y reinterpretación cristiana de este dios pagano, la podemos deducir de lo siguiente: El historiador griego Plutarco en sus "Vidas Paralelas" cuenta de un navegante que oyó una voz misteriosa que le ordenó: "Anuncia que el gran Pan ha muerto ", lo que fue interpretado posteriormente, en relación al nacimiento del cristianismo, como el grito u anuncio del fin del paganismo. ${ }^{27}$ No olvidemos que Cupido sin venda triunfa sobre Pan que representa los meros apetitos de la naturaleza. ${ }^{28}$

\section{Bautismo de San Agustín}

Casi al año de haberse convertido, el 24 de abril del 387 recibió el bautismo junto con su amigo Alipio y su hijo Adeodato de manos del obispo Ambrosio. En el lienzo aparecen estos personajes además de Mónica y otros familiares alrededor de la pila bautismal, en el marco de una arquitectura rococó y con un rompimiento de gloria en la parte superior en la que se aprecia un coro de ángeles músicos y el Espíritu Santo. En la fuente grabada se cita en latín un pasaje de San Lucas que dice: “....habrá más fiesta en el cielo por un pecador que se arrepiente que por noventa y nueve justos" (Cáp. XV, v.7).

En Las Confesiones (Lib. 9. Cap.6), Agustín se dedica a relatar su bautismo y la emoción que sintió. Escribe que lo acompañó su amigo Alipio y su hijo Adeodato de quince años, fruto de su pecado. Hacia la derecha de la escena el báculo episcopal y el panal de abejas, atributo de San Ambrosio. En este momento de la vida de Agustín es que se canta por primera vez el Te Deum, a las palabras del obispo Ambrosio: "Te Deum Laudamus": A ti Dios Alabamos. San Agustín responde: "Te Deum Confitemur": A ti Dios Reconocemos. ${ }^{29}$

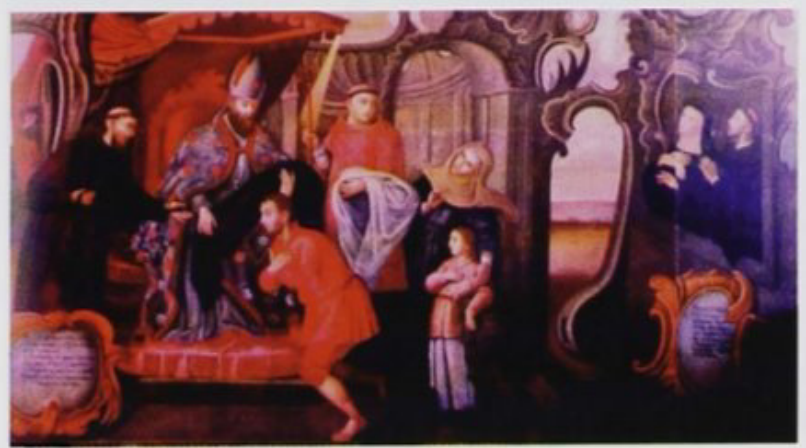

\section{Agustín recibe el hábito recomendado por la Virgen. Éxtasis de Ostia}

La pintura toma del grabado de los Klauber el tema de la Imposición del hábito a Agustín, no así la escena del Éxtasis de Ostia que aparece agregada al lado derecho de la composición, pero igualmente en el marco de una complicada arquitectura rococó en la que Mónica y Agustín se en-

25 CIRLOT, Juan Eduardo: Diccionario de símbolos. Barcelona, Edit. Labor, 1979, p. 130.

26 Ibídem, p. 164

27 PRAMPLINI, Giácomo: La Mitología en la vida de los pueblos. Barcelona, edit. Montaner y Simona S.A. Traducción de Luis Monreal Tejada. 1979, Tomo II, pp. 37-38. Ver también: OVIDIO: Metamorfosis, Madrid, Edit. Cátedra, 1997, p.227.

28 PANOFSKY E.: Ob. Cit. 1980, p.169.

29 REISINGER, F: Ob. Cit. 1990, p.75. Cita como referencia el "Sermo de bautismo et conversione Augustini" de Ambrosio que era conocido en esa época bajo la edición N. Crusenius, Monasti con Augustinianum, 1623, p. 13. También ver VORAGINE, Santiago de la: La Leyenda Dorada. Madrid, Edit. Alianza Forma, 1994, p.534. 
cuentran en arrebato místico (Fig.8). Agustín después de su bautismo y toma de hábito con su familia se dirige a Ostia, en la desembocadura del Tíber, para embarcarse a África, lugar donde ocurre esta última escena que precede a la muerte de Mónica (387) y a la partida de San Agustín de Italia.

Según la cartela del lienzo, Agustín recibe el hábito de Ambrosio con ayuda de Simpliciano el día 2 de mayo del año 387, a lo que se agrega de la leyenda del grabado en latín que fue negro con cinturón de cuero. Lo acompañan Evodio, joven del municipio que se había convertido (Conf. Lib.9. cap.8) y detrás de Agustín aparecen su madre y su hermana. La leyenda en latín también relata, basada en sus Confesiones, su estancia en Milán previa a este momento, en la hacienda Casiciaco de su amigo Verecundo, donde se había retirado después de su conversión para prepararse para el bautismo (Conf. Lib.9. Cap.3).

\section{San Agustín y la visión de la Santísima Trinidad}

Bajo la denominación considerada en este acápite figura un lienzo en la serie cusqueña que toma como referencia el grabado de los Klauber que representa el famoso encuentro de Agustín con el Niño en la playa de Centocelle (Fig.9). El anónimo pintor cusqueño tomó toda la composición de la estampa y sólo eliminó al Niño y cambió de posición a Agustín, quien se dirige hacia la aparición de la Santísima Trinidad (Fig.10). Curiosamente el tema del también llamado Niño de la Concha figura en otro lienzo de la serie cusqueña, pero está más cerca del grabado de Bolswert y la pintura de la serie de Basilio Pacheco en el convento de San Agustín de Lima.

Si nos basamos en la leyenda en latín del grabado, el hecho ocurre en África donde Agustín se aparta de los caminos inciertos de varios templos, indagando sobre el misterio de la Santísima Trinidad. Se le ve en el marco de un paisaje en contemplación de la Trinidad, mientras un ángel les ofrece el corazón del Santo. A sus pies un anciano semidesnudo al lado de un cántaro que vierte agua y que corresponde, según la leyenda de la zona inferior del grabado, a un ermitaño que venera el sitio donde Agustín comenzó la obra de la Trinidad, junto al puerto de Bertoldo, y halló las puertas del cielo. El cántaro que vierte agua simboliza el origen de un manantial, cual fue la sabiduría en los futuros escritos de Agustín sobre los dogmas de fe de la Iglesia Católica.

\section{Agustín lava los pies de Cristo peregrino}

La pintura cusqueña sigue con fidelidad al grabado de los Klauber donde aparece en la parte superior un gran título que nos orienta en la descripción y momento histórico de su vida cuando en el año 389 introduce la vida ermitaña a la vida de monasterio (Fig.11). Fue el año en que murió su hijo Adeodato. En medio de paisaje se inserta una fantástica arquitectura rococó y en ella se desarrolla la escena donde Agustín sin saberlo lava los pies a un peregrino, labor que hacía como acto de humildad y resulta ser la figura del mismo Cristo quien le dice: "Hoy mereciste ver y tocar al hijo de Dios en carne. A tu cuidado encomiendo mi Iglesia".

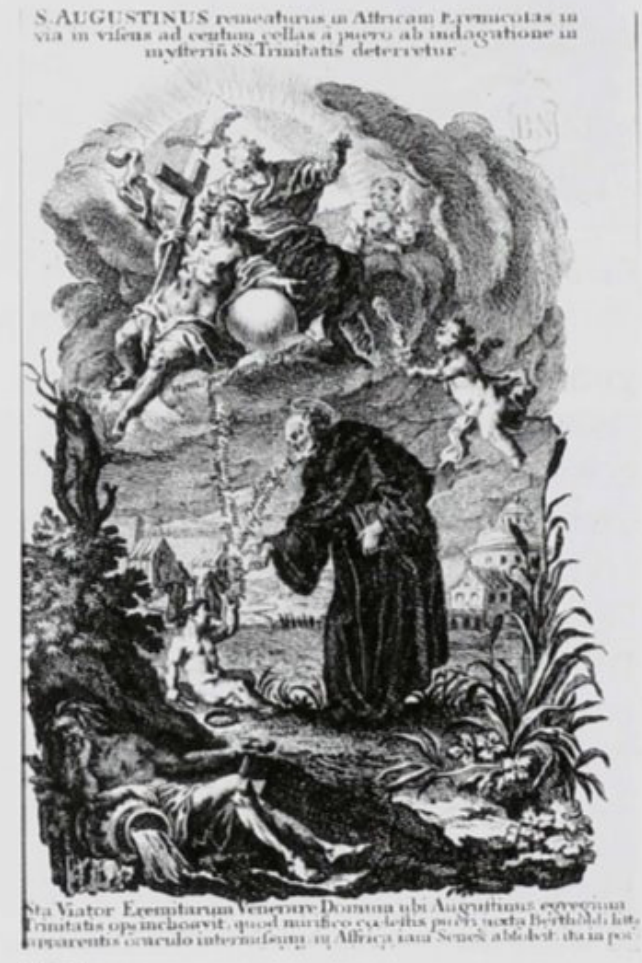

Fig. 9

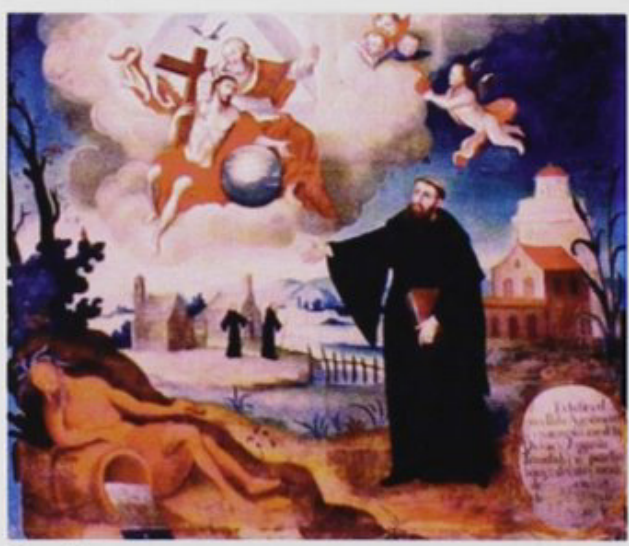

Fig. 10 


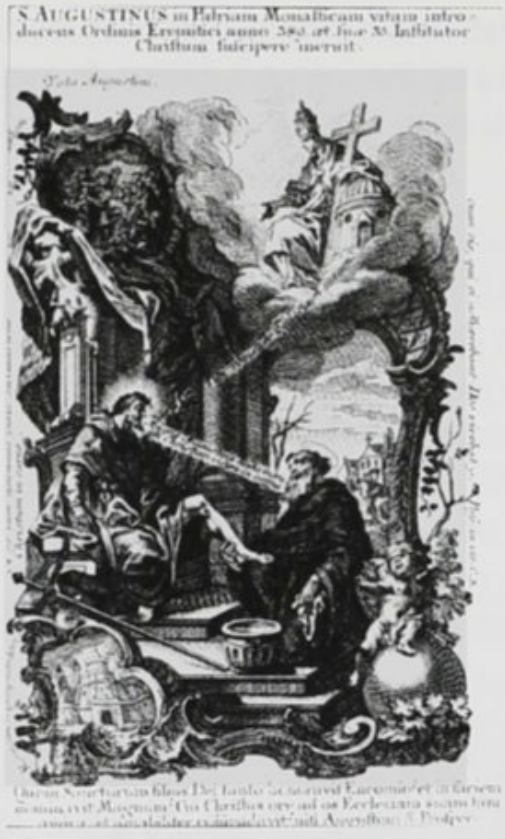

Fig. 11

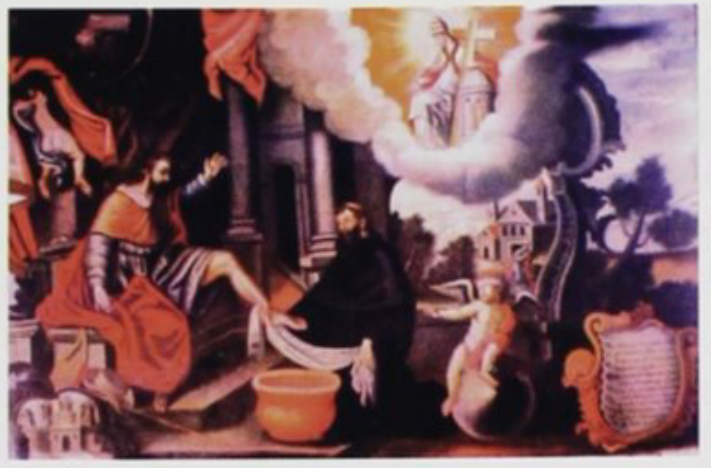

Fig. 12
Palabras escritas en latín en el grabado y que no faltan en la leyenda de la cartela del lienzo (Fig.12). En la parte superior la Alegoría de la Iglesia con leyenda circundante en latín que dice: "Con el que lo siga Dios vivirá. ${ }^{30}$ Esta leyenda en latín termina en la parte inferior en la figura del Amor Profano, al costado de Agustín, con los ojos vendados sentado sobre el mundo con su carcaj y flechas, figura pagana sometida al principio de disyunción, es decir en sentido alegórico sobre lo sensual del amor terreno abandonado por Agustín para dedicarse a Dios. ${ }^{31}$

En la serie de los grabados de los Klauber en el orden si-

guen las escenas del momento en que Agustín es obligado a ordenarse de presbítero y cuando recibe las investiduras de obispo de Hipona a petición del titular, San Valerio, no consideradas en la serie cusqueña. Igualmente vemos algunos temas que no figuran en los grabados como cuando se representa a Agustín en la fundación de su primer monasterio en Hipona y más aún una escena completamente novedosa en su iconografía internacional: San Agustín entrando a Hipona, ${ }^{32}$ donde al anacronismo de las vestiduras del siglo XVIII se suma el marco escénico de la Plaza Mayor de Lima, la Ciudad de los Reyes (Fig.13).

\section{Agustín eligiendo a sus canónigos}

La representación pictórica en composición muy apaisada se basa en el grabado de los Klauber en la que en el marco escenográfico del interior de una biblioteca, Agustín se dirige a sus clérigos regulares que están a su alrededor. A través de un arco se divisa un paisaje urbano en lontananza y en la parte superior entre nubes una mujer con una jarra y un pan.

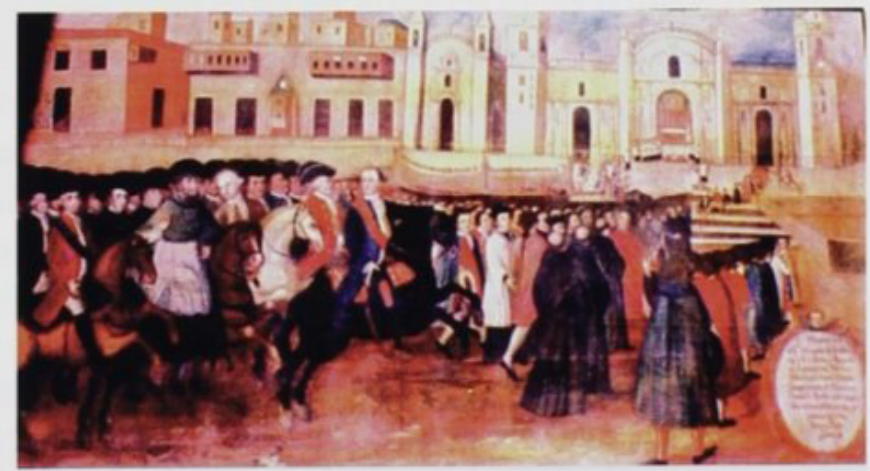

Fig. 13

La leyenda de la pintura se contradice con los escritos en latín que acompañan la estampa; mientras que en la primera el momento tiene por marco histórico la ciudad de Milán, la del grabado nos la fecha en una etapa posterior, en el año 396, cuando ya ha tomado posesión del obispado de Hipona, por la mitra que figura sobre la mesa y el báculo en la mano de un clérigo, dignidades episcopales. Además se lee en latín que Aurelio, Primado de África, lo nombra como Obispo de los clérigos regulares en esta fecha.

La mujer entre nubes es identificada como Martha y la cita nos lleva al evangelio de San Lucas (Cap. X, v. 38 a 42), donde se relata el hospedaje dado a Cristo por Martha en su camino a Jerusalén, quien se desesperaba por los quehaceres de la casa para atenderlo mientras que su hermana María se dedicaba sólo a escuchar las palabras de Jesús. Ante las quejas de

30 POSIDIO: Vida de San Agustín. Santiago de Chile, Introducción y notas del diácono Osvaldo Garay, s/f. Cap. II.

31 PANOFSKY, E.: Ob. Cit. 1980, p. 187. Ver también: ESTEBAN LORENTE, Juan F.: Ob. Cit. 1998, p. 420.

32 PAPINI, Giovanni: San Agustín Buenos Aires. Ediciones Argentinas Cóndor s/f, p. 214. Según el autor en el 396 muere Valerio y le sucede Agustín como obispo de Hipona. 
Martha por la falta de ayuda de su hermana, Jesús le dijo: "Martha tu te afanas y acongojas, distraída en muchas cosas; $y$ a la verdad que una sola cosa es necesaria. María ha escogido la mejor suerte, de que jamás será privada".

Esto refuerza la Regla Básica de San Agustín escrita sobre el libro que figura en la mesa: "Ante todo, queridísimos hermanos amemos a Dios y luego al prójimo". Agustín consideraba a estas dos mujeres bíblicas como muestras representativas de fe activa y vida contemplativa. ${ }^{33}$

\section{San Agustín, martillo de los herejes}

El encabezado de la estampa de los Klauber nos da el título igualmente para el lienzo que lo sigue fielmente: San Agustín, Doctor de la Iglesia, insigne y tenaz martillo de los herejes, en la que se reitera en la zona inferior la destrucción de los heresiarcas a través de su verbo; Pelagio, Donato, Manes y Fausto, tal como se aprecia en la primera estampa de la serie grabada, aunque con variantes compositivas, aparecen caídos por los rayos que manda un angelito detrás del Santo, mientras él escribe sentado en su biblioteca bajo la inspiración del Espíritu Santo. Del centenar de libros registrados después de su conversión aparecen varios en los estantes de la biblioteca que le sirve de fondo. Por citar algunos: Ciudad de Dios, Naturaleza y gracia contra Pelagio, Del Génesis contra los Maniqueos, Sobre la naturaleza del bien contra los maniqueos, Réplica al gramático Cresconio, donatista, Las dos almas, contra los maniqueos, entre otros. ${ }^{34}$ En el libro que escribe se lee: "El regalo de la perseverancia contra los Semipelagianos". ${ }^{35}$

\section{San Agustín entre la sangre de Cristo y la leche de María}

Para este tema el anónimo pintor cusqueño se basa en el grabado de los Klauber con fidelidad (Fig.14). Tanto en las graduaciones de grises de la calcografia como en los colores del lienzo los elementos de rocalla proliferan en arquitectura y cartela, en ambas se incluye una leyenda en latín en la cartela inferior donde se lee: "Dios que por la redención del mundo naciste, siendo circuncidado y reprobado por los judíos".

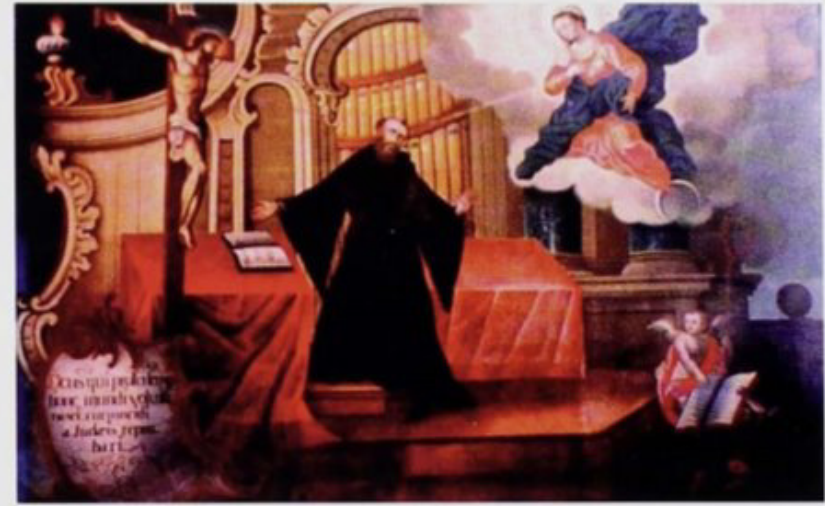

Fig. 14

La denominación del tema iconográfico está marcado por la indecisión del Santo entre la aparición a la izquierda de Cristo Crucificado que le ofrece su sangre y la Virgen María a su derecha su leche materna. Por ello, en la zona inferior del grabado se lee: No se a quien dirigirme. En cintas parlantes latinas que salen de sus labios se lee hacia Cristo: "Aqui me apaciento con la sangre" y en la dirigida a la Virgen: "Aquí me sustento con la leche".

\section{2. Éxtasis de San Agustín}

Las leyendas en latín se dedican a destacar el amor de Agustín por Dios. En un marco escenográfico arquitectónico rococó vemos al Santo sostenido por un ángel al caer en éxtasis ante la aparición de Jesús, quien le dice: Agustín ámame, a lo que él responde: De esta manera te amo Señor. Heriste mi corazón (Fig.15). La imagen-discurso nos muestra el corazón de Agustín alado y en llamas que se eleva hacia Cristo, mientras que Cupido, como símbolo de Amor Divino, ya sin venda en los ojos, con arco y flecha, apunta hacia él. El tema iconográfico en mención está relacionado con el que desarrolla Pacheco para Lima con el título de la Transverberación de Agustín, basado en las propias palabras del Santo en sus Confesiones: "Tus flechas habían atravesado mi corazón con tu amor. Llevaba tus palabras en mis entrañas".

33 REISINGER, F.: Ob. Cit. 1990, p.75.

34 PAPINI, G.: Ob. Cit. s/f, p. 211 y ss. Nos alcanza una relación de sus obras.

35 Doctrina semejante a la de Pelagio surgida al sur de Francia en el Monasterio de San Víctor de Marsella. llamada antes del siglo XVI, doctrina de los marselleses o de las Galias. 


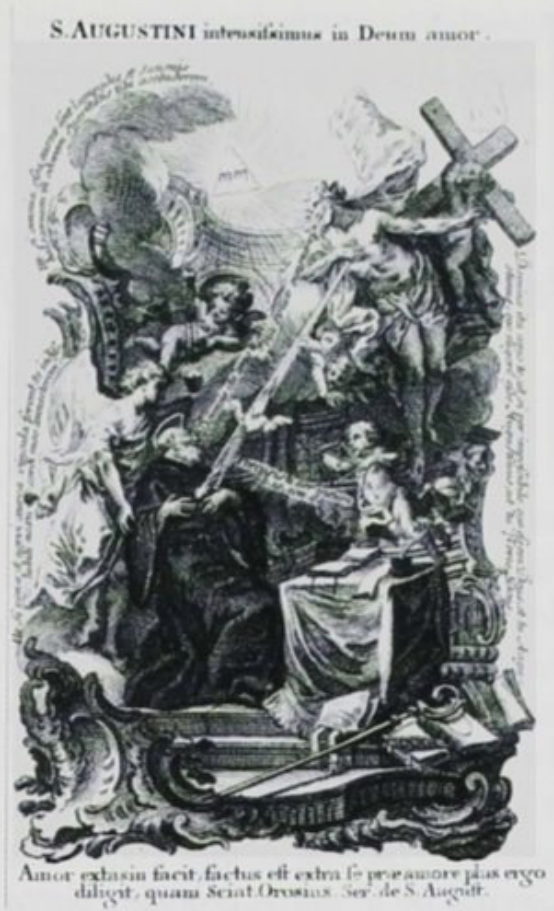

Fig. 15

Las leyendas latinas circundantes del grabado nos llevan a otro de los temas de su vida denominada: Pruebas de amor de Agustín, basado en un biógrafo tardío de Agustín. ${ }^{36}$ Tema que no falta en otro lienzo de la serie cusqueña pero sí en la serie grabada, por ello se incluye textos que aluden a las ataduras, a su sangre y sobre todo a esa frase que dice: "Si yo fuera Dios y vos fueses Agustín cediera en vos la Deidad".

La leyenda inferior resume el discurso-imagen: Dar amor es saber como mostrar ese gran amor, tomado de Paulo Orosio, historiador hispano latino visigodo que escribió Historiarum libri VII contra paganos, considerado como el primer ensayo de historia universal cristiana, de mucha influencia en la Edad Media. Orosio perseguido por los suevos, huyó a Hipona donde se convirtió en discípulo de San Agustín, hacia el año 414.

En el grabado de los Klauber, al cual sigue con fidelidad, las leyendas sólo se refieren a un éxtasis de amor a Cristo, no mencionan que antecede a su muerte tal como se hace en la leyenda de la pintura del Cusco: "Preparase para morir el grande Agustino con singulares ejercicios de eminentes virtudes y el señor lo llena de favores...".

\section{Muerte de San Agustín}

Posidio, su primer biógrafo nos relata los últimos momentos de la vida de Agustín, quien murió a los 76 años, el 28 de agosto del año 430. En su enfermedad había mandado copiar los Salmos de David llamados de la Penitencia que los colocaron en la pared, al lado de su cama, para leerlos constantemente. ${ }^{37}$ En base a las leyendas latinas del grabado y de la que acompaña el tema desarrollado en lienzo, se puede concluir que en el momento de su fallecimiento estaba acompañado por Posidio, obispo Ca-

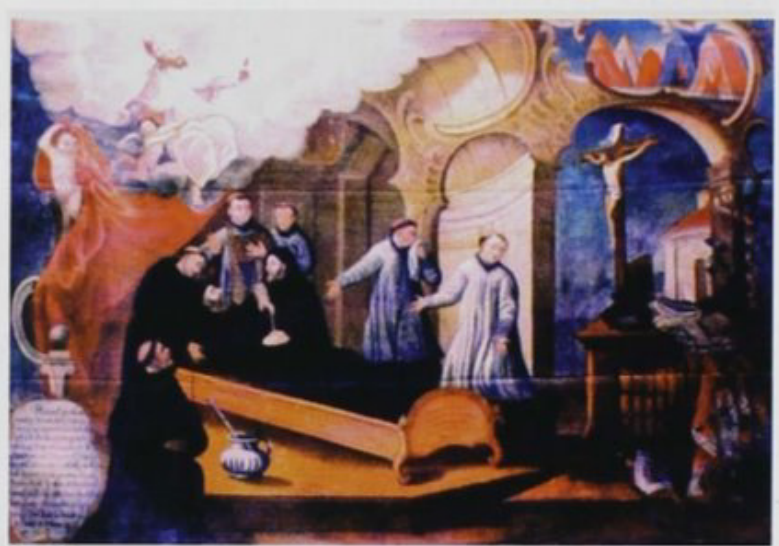

Fig. 16 tamense, y entre otros clérigos que rodean su lecho, un religioso del convento de Tagaste quien lo ve subir al cielo vestido de pontifical con el corazón en la mano y ofrecerlo a la Santísima Trinidad ${ }^{38}$ (Fig.16).

Una pequeña escena en la parte superior derecha del grabado y la pintura, enmarcada en cartela rococó, muestra un campamento, rodeada por una inscripción latina que dice: Al tercer mes de asedio murió. Se refiere a que Agustín cae enfermo y muere al tercer mes del asedio de Hipona, ocurrido durante las invasiones bárbaras dirigidas por Genserico al norte de África, iniciadas en el año 429. Pocas décadas después llegaba a su fin el Imperio Romano de occidente, en el 476.

36 LANCILOTTUS, C.: S. Aureiei Augustini...vita.Amberes, 1616, p.262. Cfr. por ITURBE, en Ob. Cit. 2001, p. 70.

37 POSIDIO, Ob. Cit. s/f. p. 54

38 En la leyenda inferior del grabado se escribe el nombre de Petrus de Natalibus Lib 7, c. 128, sin citar el libro de este escritor del siglo XV. 